\title{
Economic feasibility for the creation and maintenance of physical quantities primary measurement standards
}

\author{
Pavel Neyezhmakov ${ }^{1, ",}$, Alexander Prokopov ${ }^{1}$ \\ ${ }^{1}$ National Scientific Centre "Institute of Metrology", Myronosytska Str. 42, 61002, Kharkiv, Ukraine
}

\begin{abstract}
The Strategy of the European Association of National Metrology Institutes (EURAMET) defines the key directions for the development of regional and national metrology systems, taking into account current trends in the development of science, technology and needs of society and economies. The Strategy notes that due to the complexity and large scale of tasks their solutions is possible only by uniting the efforts of a number of countries and with regard to cost optimisation. In recent years, economic criteria hold an important place among the choice criteria for optimal ways for development of national metrology systems of member countries of Euro-Asian Cooperation of National Metrological Institutions (COOMET). There is a growing interest in research and development of methods for quantitate assessment of the economic feasibility of a particular options of implementation of the general strategy with regard to the primary measurement standards of the units of physical quantities at national, regional and international levels. This paper substantiates methodology and presents new algorithms for the evaluation of economic feasibility and cost optimisation for financing metrological activity, such as, for making a decision on the creation or improvement of the national primary measurement standards.
\end{abstract}

\section{Introduction}

The documents of EURAMET Strategy $[1,2]$ represent the key areas of the metrological activity that define requirements to be met by national and international metrology systems, taking into account current trends and prospects in development of global economy, science, and technology. To substantiate the choice of the best development option in terms of a particular metrological system within the framework of this strategy, it is necessary to carry out a comparative analysis of possible options for such a system (including a national measurement standards) in order to establish compliance with the requirements (criteria) for the areas of activities indicated in $[1,2]$. Such tasks are typical not only for metrology, but also for many other fields of activity; to solve them, a risk-based approach [3], a method of analyzing the Saaty hierarchies [4], etc. are often used that operate the quantitative data characterizing the degree to which a particular option meets the considered criteria. In the general case, these data can be obtained either on the basis of expert evaluations or by calculations, if appropriate methods are available for such calculations.

Among the criteria reflecting compliance with the considered areas of activity, an important place, according to [1,2], is occupied by criteria characterizing the economic feasibility of financing the development of metrological systems both at the international and national levels. In this regard, it should be noted that the economic aspects of metrology have long become one of the major research areas in many national metrology institutes. In particular, an extensive NIST program devoted to the study of the influence of metrology on the national economy is known [5], and similar studies are being systematically carried out in many other developed countries in the scientific, technical and economic fields [6]. This task remains relevant at the present time, since most of works on addressing metrology and economics problems that have already been completed or are in process concern only the determination of the integral economic effect from the financing of metrology, which manifests itself as an increase in profits for the economy as a whole or for its individual branches. These works are usually based on the collection and analysis of statistical data characterizing the costs for metrology and the corresponding profit for the already achieved results of production activities that generally cannot serve as a reliable basis for planning, which requires special forecast evaluations. Such evaluations should also be used when specifying action plans for the implementation of the strategic objectives, in particular, the actions aimed at improving measurement standards in connection with redefinitions of SI units.

\section{Methodology}

From the above mentioned it is obvious that the overall result of financing the metrological activity depends on the results achieved from investing in the development (provision of functioning) of the individual elements of which the metrological system consists as a whole

Corresponding author: pavel.neyezhmakov@metrology.kharkov.ua

C The Authors, published by EDP Sciences. This is an open access article distributed under the terms of the Creative Commons Attribution License 4.0 (http://creativecommons.org/licenses/by/4.0/). 
(measurement standard base, verification and calibration laboratories, etc.). Therefore, for the purposes of forecasting and substantiating decision-making related to the improvement of metrological systems, it is extremely important to use methods for quantitative evaluation of the economic feasibility of investing in a certain type of metrological activity (creating and equipping metrological laboratories for verification and calibration of measuring instruments, creating and maintaining the national measurement standards, implementation of procedures ensuring the recognition of the national measurement standards at international level, etc.). Within the framework of this particular approach, it is possible, if necessary, to take into account the mutual influence of certain elements of the metrological system on its functioning, that has been developing in recent years at the National Scientific Centre "Institute of Metrology", which performs the functions of the national metrology institute (NMI) of Ukraine. A number of results obtained using this approach have already been discussed at CIM2015 [6]. This paper presents new information on the methods of quantitative evaluation of the economic feasibility of investment in various forms of metrological activity developed using this approach, including activities aimed at creating and improving the primary measurement standards, and describes algorithms for taking into account the effect of inflation processes on the results of such an evaluation.

\section{Algorithms for evaluation of the economic feasibility of investments in metrological activity}

\subsection{The general algorithm for evaluation of the economic feasibility of investments in the metrological activity of the enterprise (laboratory)}

In the general case, which is considered below, the purpose of investments may be in increasing the capabilities of the enterprise (laboratory) as a result of the creation (or purchase) and commissioning of new metrological equipment (including the reference one) or in expanding the scope of accreditation of this enterprise for performing additional metrological works, or in implementing measures to ensure international recognition of the results of metrological works performed by the enterprise (laboratory), etc. The main idea of the discussed algorithms is to compare at least two alternative options, for each of which total costs balances (which are determined as expenses minus revenues) corresponding to a certain (the same for the considered options) time interval $N_{\text {YEARS }}$ are estimated. The scope of work of the enterprise (laboratory) and, consequently, the costs balances for each option are assumed to be different. As a more efficient (recommended) investment option, one is chosen for which the total costs balances for $N_{\text {YEARS }}$ are the smallest. That particular one is proposed for practical implementation in the enterprise (in the laboratory).
Let's consider the time interval $N_{Y E A R S}$, during which some type of metrological activity (not specified yet) is performed at an enterprise (in a laboratory). To simplify the presentation, we will consider only two alternative options of the scope of this activity; first we will neglect the change in the value of money over time (due to inflation factors) and then generalize the results obtained by introducing discounting factors into consideration similarly to [8]).

Option 1. There are have not been any changes in the activity of the enterprise during all $N_{\text {YEARS }}$. The costs balance (expenses minus revenues for $N_{\text {YEARS }}$ ), which for this option is designated as $B_{l}$, is described by the formula:

$$
B_{1}=\left(E_{1}-R_{1}\right) \cdot N_{\text {YEARS }},
$$

where $E_{1}$ and $R_{1}$ - annual expenses and revenues of the enterprise. It is assumed that in the absence of changes in activity, the annual balance of expenses-revenues also does not change.

Option 2. Two stages are considered:

- a stage of investing funds for expansion (changing) the area of metrological activity of the enterprise, which is carried out during the first $N_{I N V}$ years. At this stage, the balance $B_{I N V}$ (expenses minus revenues for $N_{I N V}$ ) is determined by the formula:

$$
B_{I N V}=\left(E_{2 I N V}-R_{2 I N V}\right) \cdot N_{I N V},
$$

where $E_{2 I N V}$ and $R_{2 I N V}$ - annual expenses and revenues at the investment stage, which are considered to be unchanged for $\mathrm{N}_{I N V}$ years;

- a stage of operation (during the subsequent $N_{O P}$ years, where $N_{Y E A R S}=N_{I N V}+N_{O P}$ ) of possibilities emerged due to the expansion (change) of the area of metrological activity. At this stage, the balance $B_{O P}$ (expenses minus revenues for $N_{O P}$ years), also with the annual expenses and revenues unchanged during $N_{O P}$ years, is determined by the same formula:

$$
B_{O P}=\left(E_{2 O P}-R_{2 O P}\right) \cdot N_{O P},
$$

where $E_{2 O P}$ and $R_{2 O P}$ - annual expenses and revenues at the operation stage.

By combining together two stages, we obtain the full costs for the second option:

$$
\begin{aligned}
& B_{2}=B_{I N V}+B_{O P}=\left(E_{2 I N V}-R_{2 I N V}\right) \cdot N_{I N V}+ \\
& +\left(E_{2 O P}-R_{2 O P}\right) \cdot N_{O P}
\end{aligned}
$$

Investing funds in order to expand (to change) the area of metrological activity of the enterprise will be economically feasible if, in comparing the $1^{\text {st }}$ and $2^{\text {nd }}$ options, inequality $B_{2}<B_{1}$ is realized, i.e.

$$
\begin{aligned}
& \left(E_{2 I N V}-R_{2 I N V}\right) \cdot N_{I N V}+\left(E_{2 O P}-R_{2 O P}\right) \cdot N_{O P}< \\
& <\left(E_{1}-R_{1}\right) \cdot N_{Y E A R S}
\end{aligned}
$$

It should be noted that the exceedance value of the righthand side of inequality (5) over the left one determines 
the investment gain received by the enterprise for the considered period.

An important point for making a decision about investing funds is determining the payback period of the investment. Let's designate the payback period as $N_{P B}$ (i.e., in determining the payback period we take $N_{O P}=N_{P B}$ ), then $N_{P B}$ value should be determined from equation

$$
\begin{aligned}
& \left(E_{2 I N V}-E_{1}+R_{1}-R_{2 I N V}\right) \cdot N_{I N V}= \\
& =\left(E_{1}-E_{2 O P}+R_{2 O P}-R_{1}\right) \cdot N_{P B}
\end{aligned}
$$

obtained from (5) by replacing the inequality sign by the equality sign (and also replacing $N_{O P}$ by $N_{P B}$ ). It follows that

$$
N_{P B}=\frac{\left(E_{2 I N V}-E_{1}+R_{1}-R_{2 I N V}\right) \cdot N_{I N V}}{E_{1}-E_{2 O P}+R_{2 O P}-R_{1}} .
$$

Thus, we obtained the condition (5) of the economic feasibility of investments in the expansion (change) of the metrological activity of the enterprise (laboratory) and the evaluation (7) of the payback period of investments in conditions where the value of money does not change (inflation is absent).

Let's summarize the results for those conditions when an account of the effect of inflation is necessary. Inflation will be taken into account by introducing a discount factor to the annual expenses and revenues in accordance with the general principles of economic theory. However, unlike the generally accepted methodology, we will use the calculation algorithm proposed in [7, 8], i.e., instead of the annual values of expenses and revenues that are change due to inflation and normalized by estimated year we will consider absolute annual values obtained by multiplying the initial estimated values, which do not take into account inflation, by $(1+r)^{i}$ (where $r$ is the discount rate, $i$ is the year number). With this, as a result of calculations, we immediately obtain the absolute values of the amounts of expenses and revenues required for the considered period. Taking into account the discount rate with $r=$ const, i.e. inflation is assumed to be constant during the considered period of time $N_{Y E A R S}=N_{I N V}+N_{O P}$, the condition of economic feasibility of investments (5) and the formula for the payback time (7) of costs takes the form [7, 8]

$$
\begin{aligned}
& \left(E_{2 I N V}-R_{2 I N V}\right) \cdot \sum_{i=1}^{N_{I N V}}(1+r)^{i-1}+a \cdot \sum_{i=1}^{N_{O P}}(1+r)^{i-1}< \\
& <\left(E_{1}-R_{1}\right) \cdot \sum_{i=1}^{N_{\text {YEARS }}}(1+r)^{i-1} \\
& N_{P B}=\frac{1}{\ln (1+r)} \times \\
& \times \ln \frac{\left(E_{2 I N V}-R_{2 I N V}\right)\left\lfloor(1+r)^{N_{I N V}}-1\right]+\left(E_{1}-R_{1}\right)-a}{\left(E_{1}-R_{1}\right)(1+r)^{N_{I N V}}-a},
\end{aligned}
$$

where $a=\left(E_{2 O P}-R_{2 O P}\right)(1+r)^{N_{I N V}-1}$.

The relations obtained are valid for any type of metrological activity. Further they will be concretized on the example of evaluation of the economic feasibility of investments in the creation (improvement) of the national primary measurement standards.

\subsection{Algorithm for evaluation of the economic feasibility of financing the works on creation (improvement) of the national primary measurement standard}

The methodology described in $\S 3.1$ of this paper and implemented in $[9,10]$ is used to substantiate the calculated algorithms. It is considered, that traceability to the primary measurement standard of the unit of measurement is provided either by the national primary standard (NPS) that has passed international comparisons and has CMCs in KCDB database (option 1), or - in cases where NPS has not been created (option 2), - by a reference (secondary) measurement standard of the country (RS). It is considered that such RS is calibrated abroad (the foreign measurement standard will be the source of the traceability through its CMCs).

When determining the annual expenses for the top element of the measurement hierarchy, $E_{M N P S}$ and $E_{M R S}$ expenses for the maintenance (operation) of NPS or RS, respectively, $E_{C R S}$ expenses for calibration of RS abroad, and $E_{C r N P S}$ expenses for the creation of NPS are taken into account. $R_{P N P S}$ and $R_{P R S}$ revenues from performing calibrations using NPS or RS, respectively, are also taken into account. As for the possible $E_{I R S}$ expenses for the improvement of $\mathrm{RS}$, as well as for $E_{I C N P S}$ expenses for international comparisons of NPS, they are not included to the annual balance, but are accounted separately in the overall balance for the total time of operation of the measurement standard. Within the considered model, the general condition (5) of economic feasibility in case of financing the works on creation (improvement) of the national primary measurement standard can be presented in the form $[9,10]$.

$$
\begin{aligned}
B^{W} & \square N_{C \mathrm{r}}+B^{S} \square N_{O}+E_{I C N P S}+E_{I R S}^{*}< \\
& <B^{A} \square\left(N_{C \mathrm{r}}+N_{O}\right)+E_{I R S}
\end{aligned}
$$

where

$B^{S}=E_{M N P S}-R_{P N P S}$ (that corresponds to $E_{2 O P}-R_{2 O P}$ in formulas (3) - (9));

$B^{A}=E_{M R S}+E_{C R S}-R_{P R S}$ (that corresponds to $E_{l}-R_{l}$ in formulas (1), (5) - (9));

$B^{W}=E_{M R S}+E_{C R S}+E_{C r N P S}-R_{P R S}$ (that corresponds $E_{2 I N V}-R_{2 I N V}$ in formulas (2), (4) - (9));

$E^{*}{ }_{I R S}, E_{I R S}$ - total expenses for the improvement of RS for the options 1 and 2, respectively;

$N_{C r}$ - years are needed to create NPS (investment period that corresponds to $N_{I N V}$ in formulas (2), (4)-(9));

$N_{O}$ - years until created standards operated (operation period that corresponds to $N_{O P}$ in formulas (3) - (5), (8), and it is obvious that $\left(N_{\mathrm{Cr}}+N_{O}\right)$ corresponds to $\left.N_{\text {YEARS }}\right)$. The stronger the inequality (10) is, the greater the economic feasibility for the creation of NPS. Costs payback time of creating the measurement standard, for which the general equation has the form (7), we obtain after transferring to the equality in (10), replacing $N_{O}$ with $t$ and solving the resulting equation 


$$
t=\frac{\left(B^{W}-B^{A}\right) N_{C \mathrm{r}}+E_{I C N P S}+E_{I R S}^{*}-E_{I R S}}{B^{A}-B^{S}}
$$

From the moment of time $t$, defined by the formula (11), the inequality (10) becomes true. In later moments of time, this inequality increases, reflecting an increase in cost savings for the maintenance of the highest element of the measurement hierarchy for the considered type of measurements. It is obvious that the savings obtained for $N_{C r}+N_{O}$ years are determined by the difference between the right and left side of inequality (10).

This method can also be used to validate the economic feasibility of improving NPS, if during its operation a need arises in reduced uncertainty of calibration from the measurement standard.

NPS that had been working before this need arose will not be able to meet the new requirements in such a case, so this situation can be considered as a signal for a new selection of the best option in condition of absence of NPS. That is, it can be considered to address the question of what is exactly feasible in this situation: to improve the existing NPS, or to create a RS with the required metrological characteristics? For making such a choice the above algorithm is extremely suitable, using which in a given situation the word "creation" shall be replaced by "improvement", and all the expenses and revenues in the formulas (10), (11) to select taking into account the raised costs of the component parts and all works due to the higher accuracy requirements. Since during the improvement the certain elements of replaced NPS can be used, it is necessary to take this into account when determining the total costs for the improvement of this NPS.

As an example, we will show the results of evaluating the economic feasibility of costs for creating the national primary measurement standard of the unit of luminous flux. Expenses and revenues were evaluated in Ukrainian hryvnia (UAH). In accordance with the calculations performed, the payback time for the creation of the measurement standard is only 4.6 years, and the expected cost savings over the lifetime of the created measurement standard are about 1 million UAH. Exactly these performance indicators have played a crucial role in the decision on the creation of this national measurement standard, which is currently one of the most frequently used measurement standards of Ukraine.

\subsection{Influence of inflationary processes on evaluation of economic feasibility and payback time}

Mathematical models listed above (in $\S 3.2$ ) have been designed with the assumption of fixed prices for works and services, including materials and components during the time period being considered (life cycle of the measurement standard), which includes the period of its creation and use. To take inflation into account using the scheme given in $\S 3.1$, a discounting factor $r$ is introduced to the annual expenses and revenues. As a result, formulas (10), (11) are transformed to the form

$$
\begin{aligned}
& B^{W}\left[(1+r)^{N_{C r}}-1\right]+B^{S}(1+r)^{N_{C r}-1}\left[(1+r)^{N_{O}}-1\right]< \\
& <B^{A}\left[(1+r)^{N_{C r}+N_{O}}-1\right]+r \cdot B_{M B}
\end{aligned}
$$

where the value $B_{M B}=E_{I R S}-E_{I R S}^{*}-E_{I C N P S}$ has also account for inflation changes of the components that form it, and

$$
\begin{aligned}
& t=\frac{1}{\ln (1+r)} \times \\
& \times \ln \frac{B^{W}\left[(1+r)^{N_{C r}}-1\right]+B^{A}-B^{S}(1+r)^{N_{C r}-1}-r B_{M B}}{B^{A}(1+r)^{N_{C r}}-B^{S}(1+r)^{N_{C r}-1}}
\end{aligned}
$$

It is not difficult to show that at $r \rightarrow 0$ the relations (12) and (13) transfer into relation (10), (11), respectively (under condition of correct expansion of uncertainties occurred at such transfer).

It results from the analysis (11), (13) we see that inflation accounting reduces time of the payback of expenses. At the same time, it is also confirmed by the results of time estimation of the payback of expenses while creating the national primary measurement standards at the NSC "Institute of Metrology". For example, it is shown, that inflation accounting reduces time of the payback of expenses for the creation of measurement standard of the unit of volumetric activity of radon by about 2.5 years, and for the measurement standard of luminous intensity such decrease makes for about 2 years. Such estimations are in accordance with the maintenance practice of the relevant measurement standards.

\section{Conclusion}

The considered algorithms of quantitative evaluation of economic feasibility of investments in metrological activity in the previous sections of the paper can serve as the basis for a comparative analysis of various options for such activity according to economic criteria, including criteria (requirements) corresponding to areas set out by EURAMET strategic documents, in order to substantiate the best option for implementation of this activity. As a quantitative characteristic that allows recalculation of the considered criteria into expert evaluations used in known methods (for example, such as risk-based approach [3], method of analyzing the Saaty hierarchies [4]), it is feasible to use the payback time of investments, the principles of calculation of which are substantiated in this paper.

\section{References}

1. EURAMET 2020 Strategy Version 1.1 (05/2015), https://www/euramet.org/index.php?id=documents.

2. Strategic Research Agenda for Metrology in Europe Version $\quad 1.0 \quad(03 / 2016)$, https:/www.euramet.org/research-innovation/srasurvey/

3. A.M. Dowell, and D.C. Hendershot, Simplzjied Risk Analysis - Layer of Protection Analysis (LOPA), AIChE 2002 National Meeting (2002) 
4. L. Saaty Thomas, "Fundamentals of the Analytic Hierarchy Process", RWS Publications, 4922 Ellsworth Avenue, Pittsburgh, Pa. 15413 (2000).

5. Summary of NIST Laboratory Economic Impact Studies,

http://www.nist.gov/director/planning/summarystudies.cfm

6. G. Williams, "The assessment of the economic role of measurement and testing in modern society," European Measurement Project Report, July 2002, http://www.bis.gov.uk/assets/bispartners/nmo/docs/ nms/economics_of_measurements_july2002.pdf

7. A. V. Prokopov, L. N. Krasokha, Yu. A. Yegorov, "Method for evaluation of the economic feasibility of investments in metrological activity", Newsletter of Engineering Academy of Ukraine, No.3-4, 264-267, (2008), in Russian.

8. L. M. Krasokha, O. V. Prokopov, "Evaluation of the economic feasibility of creation the national measurement standards taking into account inflation factors", Ukrainian Metrological Journal, No.1, 8-11, (2008), in Ukrainian.

9. P. I. Neyezhmakov, A. V. Prokopov, "Evaluating the Economic Feasibility of Creating National Primary Standards", Measurement Techniques, vol. 57, Issue 4, 373-377, (2014).

10. Pavel Neyezhmakov, Alexander Prokopov "Estimation of economic feasibility of development of national measurement standards", Proceedings of $17^{\text {th }}$ International Congress of Metrology, September 21 - 24, 2015, Paris, France, $190010 \quad$ (2015) available at http://dx.doi.org/10.1051/metrology/20150019001 